\title{
Quina és la funció del gen clonat?
}

\author{
Margarita Soriano, IES Verdaguer, Barcelona (bacillussubti@yahoo.es) \\ Francisca Guerola, IES Frederic Mompou, St. Vicenç dels Horts (mquerola@xtec.net)
}

Presentem una activitat didàctica complementària per a alumnes de segon de batxillerat. A partir d'una seqüència de nucleòtids del genoma de Paenibacillus barcinonensis determinem la regió codificant d'un gen, la proteîna corresponent i la seva funció. Com a annex s'inclou el guió per a l'alumnat.

Per a l'alumnat de Batxillerat no és fàcil entendre el desenvolupament i l'aplicació de la genètica molecular i la enginyeria genètica, ja que són temes molt nous que estan evolucionant constantment. Una part fonamental de la nostra feina és ajudar-los a aconseguir-ho.

En aquesta activitat els alumnes posen en pràctica conceptes estudiats a diferents unitats didàctiques estudiades anteriorment: Proteïnes, Enzims, Microbiologia, Genètica molecular i Enginyeria genètica.

Al proposar aquesta pràctica pretenem:

- Acostar als alumnes el treball científic real de un laboratori modern de genètica.

- Fer un repàs de la biologia de segon de batxillerat.

- Veure la relació entre la seqüenciació de genomes i la traducció a proteïnes, fent-los conscients de la dificultat i meticulositat d'aquest treball.

Al final l'alumne ha de produir un text explicatiu de tots els processos que ha seguit en l'activitat.

\section{INTRODUCCIÓ}

L'objectiu global de la Genètica és l'anàlisi de l'estructura i funció dels genomes i dels gens.

Les primeres evidències sobre la funció dels gens van sorgir de l'observació de correlacions entre determinades mutacions i la deficiència d'un enzim o d'altre tipus de proteïnes. La comprensió de l'estructura i funció dels gens va experimentar un gran avenç quan es va establir la relació entre la presència de mutacions en un gen i la presència de canvis d'aminoàcids específics en la proteïna corresponent. Aquests coneixements, junt amb el descobriment de la naturalesa del DNA i del codi genètic, van ser molt importants per posar de manifest la naturalesa bàsica del gen.

Malgrat això, abans de l'últim terç del segle $X X$ el seu estudi havia estat només per mitjans indirectes, mai s'havia aïllat un gen ni analitzat la seva seqüència. Encara que s'havia aïllat DNA a partir de teixit viu, amb una consistència de massa molt viscosa, com podria aïllar-se un gen específic entre aquesta "massa de fills embolicats"?

L'enginyeria genètica ho ha fet possible, i en l'actualitat s'aïllen gens i altres parts del genoma rutinàriament.

L'aïllament de gens ens permet:

- la determinació de la seqüència nucleotídica i a partir d'aquesta informació es poden establir les característiques del gen

- la comparació entre les seqüències de DNA de diferents gens pot proporcionar informació sobre la seva evolució

- la determinació de la seqüència d'aminoàcids mitjançant la conversió de la seqüència de nucleòtids dictada pel codi genètic, i a partir d'aquesta conèixer la funció de la proteïna

- l'estudi de la modificació de la seqüència de nucleòtids per determinar la funció de cada aminoàcid en la proteïna

- la generació d'organismes transgènics (organismes amb gens procedents d'altres organismes), per la utilització en la investigació tant bàsica com aplicada 
Avui dia la determinació de la funció d'una proteïna s'ha facilitat molt degut a la creació i publicació de bases de dades d'accés públic. Una de les més importants i utilitzades és SwissProt, a la qual es pot accedir a través del sistema ExPASy (fig. 1) de l'Institut Suís de Bioinformàtica.

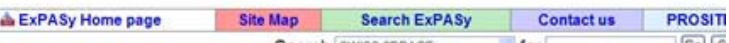

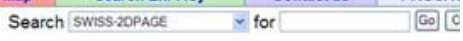

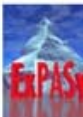

\section{ExPASy Proteomics tools}

The tools marked by $\mathrm{A}$ are local to the ExPASy server. The remaining tools are developed and host [Protein identification and characterization] [DNA $\rightarrow$ Protein] [similarity searches] [Pattern and profile searcl [Topology prediction] [Primary structure analysis] [Secondary structure prediction] [Tertiary structure] [s [Biological text analysis]

Protein identification and $\mathrm{ch}$ - Aldente $\mathrm{d}$ - Identify proteins with peptide mass fingerprinting data. A new, fast and powerful toc transformation for spectra recalibration and outlier exclusion. Download the stand-alone version FindMod $\mathrm{A}$ - Predict potential protein post-translational modifications and potential single aminc Experimentally measured peptide masses are compared with the theoretical peptides calculate user-entered sequence, and mass differences are used to better characterize the protein of intt Find Pept a- Identify peptides that result from unspecific cleavage of proteins fir preir experi Glycomod A-Predict possible oligosaccharide structures that occur on proteins from their exp for free or derivatized oligosaccharides and for glycopeptides)

Figura 1. Web del sistema ExPASy

Cada seqüència de proteïnes és una fitxa de SwissProt, en la qual, a més de la estructura primària de la proteïna, també ens ofereix altres tipus d'informacions organitzades en diferents camps. Al voltant de SwissProt s'han desenvolupat altres bases de dades i utilitats per a extraure la màxima informació possible a partir de la estructura primària de les proteïnes.

Els diferents exercicis que proposem permetran descobrir SwissProt i altres bases de dades i utilitats.

Després de la seqüenciació completa del genoma humà l'abril del 2003, les bases de dades que organitzen tota la informació del genoma humà estan adquirint cada vegada més importància. Una d'elles és la anomenada GeneCard. En aquest tipus de bases de dades podem trobar, entre altres coses, la localització cromosòmica de qualsevol gen humà, variants polimòrfiques o SNPs (Single Nucleotide Polymorphism), gens homòlegs en altres eucariotes, etc. Per això és important que l'alumnat tingui contacte amb aquest tipus d'informació.

\section{Identificació i anàlisi d'una seqüència de DNA}

La majoria de seqüències de proteïnes que s'incorporen a les bases de dades provenen de la traducció de seqüències de DNA procedents de projectes genoma. Per aquest motiu s'han desen- volupat una sèrie de tècniques bioinformàtiques per a localitzar les regions codificants i predir la possible funció de la proteïna codificada, així com per a localitzar en el DNA regions reguladores, zones repetitives, etc.

A l'hora de seqüenciar el DNA hem de tenir en compte si es tracta d'un organisme procariota (només té introns) o eucariota (té introns i exons).

La caracterització d'un fragment de DNA genòmic d'un organisme eucariota és més complicada. En aquest cas és necessari predir els llocs exactes on comencen i acaben tant els introns com els exons. Encara que per a les prediccions disposem de guies, com per exemple els llocs consens de splicing, sempre hi ha una certa incertesa amb els resultats. A més, en els gens eucariòtics es dóna el fenomen de splicing alternatiu, el qual dificulta més la definició del lloc de splicing. D'aquesta manera, no sempre un gen codifica una única proteïna. És per això que la pràctica que us proposem parteix del genoma d'un organisme procariota. Creiem que per l'alumnat de batxillerat i per als objectius que volem aconseguir és suficient.

Hem de recordar a l'alumnat que quan es tradueix un fragment de DNA és important definir quina serà la pauta de lectura o open reading frame (ORF) que s'utilitzarà. Recordem que hi ha sis pautes de lectura diferents (tres per a una cadena i tres més per a la cadena complementària) per a traduir un fragment de DNA, segons que es comenci per la primera, segona o tercera base del fragment de DNA i el bri de DNA que és transcrigui en viu.

És per això que els traductors informàtics donen 6 possibles pautes de lectura, 3 forward i 3 reverse. D'aquestes 6 possibilitats normalment s'escull la pauta de lectura més probable: llavors es diu que s'ha fet una conceptual translation, és a dir, s'ha triat la regió codificant més probable.

Una vegada coneguda l'estructura primària més probable de la proteïna es pot predir quina és la funció que té. Per fer-ho es busca en les diferents bases de dades a quines proteïnes ja seqüenciades s'assembla la nostra seqüència problema. Si hi ha un nivell de similitud elevat al llarg de tota la proteïna i només es troben similituds amb una única funció, es pot atribuir aquesta funció a la proteïna problema.

\section{Objectius}

El que es pretén en aquesta activitat està ben relacionat amb els objectius de la matèria de Biologia de Batxillerat: 
- Conèixer les tècniques de seqüenciació d'un gen

- Entendre els mecanismes de duplicació, transcripció i traducció (objectiu terminal 37)

- Investigar l'existència de pautes de lectures (ORFs) en una seqüència de DNA (procediment 2.1)

- Identificar la funció de seqüències problema de DNA i proteïnes (Investigar la funció d'un gen)

- Evidenciar la relació existent entre diferents temes (Estructura de les Macromolècules, Proteïnes, Enzimologia, Genètica Molecular, Enginyeria Genètica, Biologia Cel·lular, Microbiologia)

- Orientar-se en l'embolic de les xarxes de bases de dades de seqüències (procediment 2.1)

- Accedir a recursos genòmics, proteòmics i bibliogràfics

- Aprendre a organitzar la informació obtinguda (procediment 3.1)

- Redacció de la memòria de forma rigorosa i concreta, en estil científic (procediment 4)

\section{PRÀCTICA I COMENTARIS PER AL PROFESSORAT}

\section{Objectiu}

En la següent pràctica volem replicar, transcriure i traduir un gen clonat en un plasmidi. D'aquesta manera podrem conèixer la seqüència d'aminoàcids i a partir d'ella identificar la seva funció.

A partir del fragment de DNA seqüenciat, inserit en el plasmidi, hem de:

- Replicar el fragment de DNA (objectiu terminal 37).

- Transcriure la seqüència de nucleòtids (objectiu terminal 37)

- i posteriorment traduir-la (objectius terminals 37 i 38),

- saber quina és la part del fragment de DNA que correspon al gen que volem investigar (objectiu terminal 36)

- i conèixer la funció de la proteïna (objectius terminals 8 i 33).

Cal tenir en compte que el DNA bacterià no té introns. Això significa que cada gen codifica per a una proteïna.

\section{Continguts de la pràctica}

Fets:

5.7 Replicació i expressió del material genètic.

\section{Procediments:}

1 Realització i valoració d'experiències

2.1 Utilització de material telemàtic

3.1 Elaboració de protocols de pràctiques

3.5 Formulació de conclusions

4.1 Expressió per escrit, de la informació obtinguda a partir de l'anàlisi dels processos de transcripció i traducció.

4.2 Utilització del llenguatge científic.

4.3 Elaboració i presentació de treballs

5 Aplicació de conceptes estudiats a situacions reals

Valors:

1 Valoració crítica de la Biologia, així com de les seves aplicacions.

3 Interès per les relacions que existeixen entre la Biologia, la societat i la tecnologia.

\section{Materials}

Les bases de dades $i$ eines que necessitaràs per a resoldre l'activitat les pots trobar al full de pràctiques i al Protein Analysis System (ExPASy: http://www.expasy.ch/tools/). Aquesta serà la pàgina a què pots dirigir-te per a triar l'eina adequada en cada ocasió i respondre les preguntes plantejades.

A més, has de tenir en compte que:

- Al llarg de la sessió s'han de guardar les adreces utilitzades per posar-les com a bibliografia.

- Cal guardar tota la informació que es trobi en un disc 0 a la memòria USB per a poder respondre així a les preguntes i presentar un informe final de les pràctiques. No s'ha de deixar res en el disc dur de l'ordinador ja que l'endemà podria no estar allí.

\section{Mètode}

A partir d'una seqüència de nucleòtids hem de trobar el gen que volem investigar.

tcaggctccgtacaaggggtgagcccgcagggtgcctgtagacaa gccagcggcttgtttatcaaattacttaaattaagggaggatgttgat gatgaaaaaaatgttaacgctcttgctgtctgccggtcttgttgcttcc atattggtgtaatgcctgccgcggctgcgccaaccgtcgtcaattcaa cgatcgttgtaccgaagggcacgacctatgatggacaggggaaaa cctttgtagcgaatccctctacattaggtgacggttctcaagcggagaa tcagaagcctgtattccggctggaagcaggggcaactttgaaaaatg ttattattggtgcacccgcagcggatggtgtgcattgttacggcagctgt aatatttccaacgttgtatgggaagatgtaggcgaggatgcattgaca ctgaaatcatcaggaaccgttaatattaccggcggagcagcgtataa 
ggcttacgataaagtgtttcagatgaacgcttcgggtacgattaatatc aaaaactccgtgcggatgatatcggcaagctggtgcggcaaaatg gaggaacctcctatgcggttaacatgacactggataattccaacatat ccaacgtgaaggattccattatgcgcacggacagcagtgtatctcaa gggaagatcacgaacacacgttactccaaagtgccaacgctgttca agggctttgcttcaggcaagacgagccagtccggaaatacacagta ttaacgcacgcttgcagtaaaaaataaagaagcggctgaagttcaa gtaccacctgctcagccgttgaggagaaccaaataaaacgggatg aaccagtcaacatggcctcatcccgtttgatttggtttgtttggttacagc catgaatctgtatccatatcgaattacttctctccaggcacctcaacga acagtttgccttgggatggagcagcagaaccgctatccaaggagcc ggatttgttcatgatctcataagcggtttcctccagcatgcgagaatattt gaaggataccagcgttttccggctacagatggacgggttcctgcctc ggcaacgggtttgccttgataaagaacaggtcaccaatggttccgg cttgtttgctcagattggcttgccatttcaacagtgcatttccgttctccatc gtataataactgaccaga

1. Abans de ficar-nos en feina practicarem la replicació, transcripció i traducció a partir d'una petita seqüència de nucleòtids.

Copia la seqüència de nucleòtids senyalada en negreta. Fes la cadena complementària d'aquesta seqüència. A continuació transcriu i tradueix la seqüència (fig. 2). El resultat és a la Figura 3.

\begin{tabular}{|c|c|c|c|c|c|c|c|c|c|c|c|}
\hline & \multicolumn{8}{|c|}{ Segona lletra } & & \\
\hline & & $\mathrm{l}$ & & $\mathrm{C}$ & & 7 & A & C & & & \\
\hline \multirow{4}{*}{ 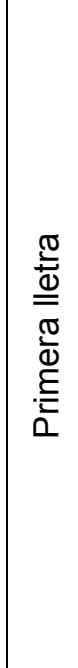 } & $U$ & $\begin{array}{l}\text { UUU } \\
\text { UUC } \\
\text { UUA } \\
\text { UUG }\end{array}$ & $\left\{\begin{array}{l}\text { Fen } \\
\text { Leu }\end{array}\right.$ & $\begin{array}{l}\text { UCU } \\
\text { UCC } \\
\text { UCA } \\
\text { UCG }\end{array}$ & Ser & $\begin{array}{l}\text { UAU } \\
\text { UAC } \\
\text { UAA } \\
\text { UAG }\end{array}$ & $\left\{\begin{array}{l}\text { Tir } \\
\text { Stop }\end{array}\right.$ & $\begin{array}{l}\text { UGU } \\
\text { UGC } \\
\text { UGA } \\
\text { UGG }\end{array}$ & $\begin{array}{l}\text { Gln } \\
\text { Stop } \\
\text { Trp }\end{array}$ & $\begin{array}{l}U \\
C \\
A \\
G\end{array}$ & \multirow{4}{*}{ 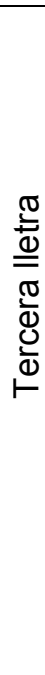 } \\
\hline & C & $\begin{array}{l}\text { CUU } \\
\text { CUC } \\
\text { CUA } \\
\text { CUG }\end{array}$ & Leu & $\begin{array}{l}\text { CCU } \\
\text { CCC } \\
\text { CCA } \\
\text { CCG }\end{array}$ & Pro & $\left.\begin{array}{l}\text { CAU } \\
\text { CAC } \\
\text { CAA } \\
\text { CAG }\end{array}\right\}$ & $\begin{array}{l}\text { His } \\
\text { Gln }\end{array}$ & $\begin{array}{l}\text { CGU } \\
\text { CGC } \\
\text { CGA } \\
\text { CGG }\end{array}$ & Arg & $\begin{array}{l}\text { U } \\
\text { C } \\
A \\
G\end{array}$ & \\
\hline & A & $\begin{array}{l}\text { AUU } \\
\text { AUC } \\
A \cup A \\
A \cup G\end{array}$ & $\begin{array}{l}\text { lle } \\
\text { Met }\end{array}$ & $\begin{array}{l}\text { ACU } \\
\text { ACC } \\
\text { ACA } \\
\text { ACG }\end{array}$ & Tre & $\left.\begin{array}{l}\text { AAU } \\
\text { AAC } \\
\text { AAA } \\
\text { AAG }\end{array}\right\}$ & $\begin{array}{l}\text { Asn } \\
\text { Lis }\end{array}$ & $\left.\begin{array}{l}\text { AGU } \\
\text { AGC } \\
\text { AGA } \\
\text { AGG }\end{array}\right\}$ & $\begin{array}{l}\text { Ser } \\
\text { Arg }\end{array}$ & $\begin{array}{l}U \\
C \\
A \\
G \\
\end{array}$ & \\
\hline & G & $\begin{array}{l}\text { GUU } \\
\text { GUC } \\
\text { GUA } \\
\text { GUG }\end{array}$ & Val & $\begin{array}{l}\text { GCU } \\
\text { GCC } \\
\text { GCA } \\
\text { GCG }\end{array}$ & Ala & $\left.\begin{array}{l}\text { GAU } \\
\text { GAC } \\
\text { GAA } \\
\text { GAG }\end{array}\right\}$ & Asp & $\begin{array}{l}\text { GGU } \\
\text { GGC } \\
\text { GGA } \\
\text { GGG }\end{array}$ & Gli & $\begin{array}{l}U \\
C \\
A \\
G\end{array}$ & \\
\hline
\end{tabular}

Figura 2. Pauta per a la lectura de seqüències de mRNA.

\begin{tabular}{|lllllllllllllllll|}
\hline 1 & TAA & GGG & AGG & ATG & TTG & ATG & ATG & AAA & AAA & ATG & TTA & ACG & CTC & TTG & CTG \\
DNA & ATT & CCC & TCC & TAC & AAC & TAC & TAC & TTT & TTT & TAC & AAT & TGC & GAG & AAC & GAC \\
mRNA & UAA & GGG & AGG & AUG & UUG & AUG & AUG & AAA & AAA & AUG & UUA & ACG & CUC & UUG & CUG \\
Aa & Stop & Gly & Arg & Met & Leu & Met & Met & Lys & Lys & Met & Leu & Thr & Leu & Leu & Leu \\
& & & & & & & & & & & & & & \\
2 & T & AAG & GGA & GGA & TGT & TGA & TGA & TGA & AAA & AAA & TGT & TAA & CGC & TCT & TGC & TG \\
DNA & A & TTC & CCT & CCT & ACA & ACT & ACT & ACT & TTT & TTT & ACA & ATT & GCG & AGA & ACG & AC \\
mRNA & U & AAG & GGA & GGA & UGU & UGA & UGA & UGA & AAA & AAA & UGU & UAA & CGC & UCU & UGC & UG \\
Aa & & Lys & Gly & Gly & Cys & Stop & Stop & Met & Lys & Lys & Cys & Stop & Arg & Ser & Cys & \\
3 & TA & AGG & GAG & GAT & GTT & GAT & GAT & GAA & AAA & AAT & GTT & AAC & GCT & CTT & GCT & G \\
DNA & AT & TCC & CTC & CTA & CAA & CTA & CTA & CTT & TTT & TTA & CAA & TTG & CGA & GAA & CGA & C \\
mRNA & UA & AGG & GAG & GAU & GUU & GAU & GAU & GAA & AAA & AAU & GUU & AAC & GCU & CUU & GCU & G \\
Aa & & Ser & Glu & Asp & Val & Asp & Asp & Glu & Lys & Asn & Val & Asn & Ala & Leu & Ala & \\
\end{tabular}


a) De la seqüència estudiada on podria començar una hipotètica proteïna?

Els alumnes han de saber que el primer triplet que es tradueix és, normalment, l'AUG, que correspon a la metionina, per tant, la proteïna ha de començar per aquest aminoàcid. En aquest cas hi ha tres metionines juntes. Podria ser qualsevol de les tres. Per precisar més hauríem de conèixer la distància a senyals consens. Són seqüències que es troben a una distancia determinada dels codons d'iniciació, i que s'aparellen amb l'extrem 3' del rRNA 165 del ribosoma. En procariotes són semblants a TTGACA (a una distància de 35 nucleòtids de AUG) i a TATAAT (a una distància de 10 nucleòtids del codó AUG). Es mostren assenyalats en blau en la seqüència.

EI DNA bacterià presenta una estructura circular de doble cadena. Això significa que el nostre gen pot estar en qualsevol de les dues cadenes. Com les seqüències poden ser molt llargues, podem tenir la seqüència del gen en la cadena original o en la complementària, i a la vegada cadascuna pot tenir tres pautes de lectures o ORF (open reading frame), en els laboratoris es treballa amb programes que ens transcriuen i tradueixen la seqüència de la hipotètica proteïna.

b) A l'exercici a) has traduït la seqüència de mRNA utilitzant una pauta de lectura. A continuació, torna a traduir la seqüència de mRNA utilitzant les altres 2 pautes de lectura. La seqüència d'aminoàcids és la mateixa?

Aquest exercici s'aconsella que es faci en grups de dos alumnes, així podran comparar el resultat de les seqüències d'aminoàcids (fig. 3 ) i comentarles. Posteriorment, es farà una posada en comú del grup classe.

2. A partir de la seqüència de nucleòtids completa donada al principi de la pràctica, la replicarem, transcriurem i traduirem amb un programa informàtic per trobar la seqüència de la hipotètica proteïna:

- Primer, anirem a la següent pàgina: http://www.expasy.ch/tools/

- Clicarem sobre la següent opció: DNA $\rightarrow$ Protein

- A continuació farem dos clics sobre: Translate

- Enganxa la seqüència de nucleòtids en el quadre en blanc (fig. 4)

- Per últim clica sobre Translate sequence

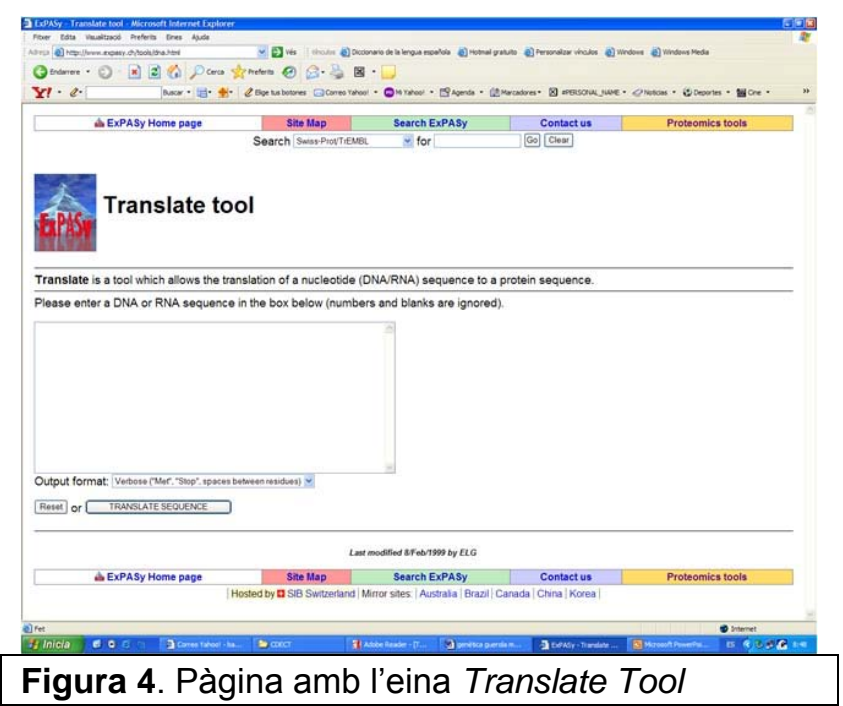

\section{Resultats}

c) Enganxa els resultats.

\section{Translate Tool - Results of translation}

\section{5'3' Frame 1}

$S G S \vee Q G \vee S P Q G A C R Q A S G L F I K L L$ KLREDVDDEKNVNALAVCRSCCFH I W C N A CR G C A NRR Q F NDRCTEGH D L Stop W T G E N L C S E S L Y I R Stop R F S S GESEACIPAGSRGNFEKCYYWCT R S G W C A L LR Q L Stop Y F Q R C Met G R C R R G C I D T E I I R N R Stop Y Y R R S S V Stop G L R Stop S V S D E R F G Y D Stop Y Q K $L P C G$ Stop $Y R Q A G A A K W R N L L C G$ Stop H D T G Stop F Q H I QR E G F H Y A H G QQCISREDHEHTLLQSANAVQGLC FR Q DEP V R K Y T V L THA C S K K Stop R S G Stop S S S T T C S A V E E N Q IKR D E P V N Met AS SRFDLVCLVTA Met NLYPYR I T S L Q A QR T V C L G Met E Q Q NRYPR S R I C S Stop S H K R F P P A C E N I Stop R I P A F F R L Q Met D G F L P R Q R V L P Stop Stop R T GHQWFRLVCSDWLAISTVHFRS P S Y N N Stop P

\section{5'3' Frame 2}

(La part ombrejada en gris correspon a la proteïna buscada).

Q A P Y K G Stop A R R V P V DKP A A C L S N $Y L N$ Stop $G R$ Met $L$ Met Met KK Met $L T L L L S$ A G L VAS I F G V Met PAAAAPTVVNSTI VVPKGTTYDGQGKTFVANPSTLGD 
GS Q A E N Q KPVFRLEAGATLKNVIIG A P A A D G V HCYGSCN I N V VWEDV GEDALTLKSSGTVNITGGAAYKAY D KVF Q Met NASG T INIKNFRADDIGK LVRQNGGTSYAVN Met TLDNSNISN VKDSIMet RTDSSVSQGKITNTRYS K V P T L FK G F A S G K T S Q S G N T Q Y Stop R T L A VKNKE A A E V Q VP P A Q P L R R T K Stop N G Met N Q S T W P H P V L I W F VWL QP Stop I C I H I E L L L R H L N E F A L GW S SRTAIQ G A G F VHDLISGFLQ HARIFEGYQRFSG YRWTGSCLGN GF C LDKE Q VTNGSGLFAQIGLPFQ QCISVLHRIITDQ

\section{5'3' Frame 3}

R L R TR G E P A G C L Stop T S Q R L V Y Q I T Stop I K G G C Stop Stop Stop K K C Stop R S C C L P V L L L P Y L V Stop C LPR LR Q P S S I Q R S L Y R R A R P Met Met D R G K P L Stop R I P L H Stop V T V L KRR IR S L Y S G WK Q G $Q L$ Stop K Met L L L V H P Q R Met V C IV T A A V I F P T L Y G K Met Stop A R Met H Stop $H$ Stop N H QE P L I L P A E QR I R L T I K C FR Stop T LR VR L I S K T S V R Met I S A S W C G $K$ Met E E P P Met R L T Stop H W I I P T Y P T Stop R I P L C ARTA VYLKGRSRTHVTP KCQRCSRALLQARRASPEIHSINA R L Q Stop K I K K R L K F K Y H L L S R Stop G E P N K T G Stop T S Q H G L I P F Stop F G L F GYSHESVSISNYFSPGTSTNSLPW D G A A E P L SKEPDLF Met I S Stop A V S S $S$ Met REYLKDTS VFPATDGRVPASA TGF A L IKNRSP Met VPACLLRLACHF N S A F P F S IV Stop Stop L TR

\section{3'5' Frame 1}

SGQLLYDGERKCTVE Met A S Q SEQT S R N H W Stop P V L Y Q G K TR C R G R N P S I C S R KNA G I L Q I F S H G G NRL Stop D $H E Q$ I R L L G Stop R F C C S I P R Q T V R Stop G A WRE V IR Y G Y R F Met A V TKQT KSKRDEA Met LTGSSRFIWF S TAE $Q \vee V L E L Q P L L Y F L L Q A C \vee N T \vee Y F R T$ G S S C L K Q S P Stop T A L A L W S N V C S Stop S S L E I H C C P C A Stop W N P S R W I C W N Y P V S C Stop P H R R F L H F A A P A C R Y H P H G S F Stop Y Stop S Y P K R S S E T L Y R K P Y T L L R R Stop Y Stop R F L Met I S V S Met HPRLHLPIQRWKYYSCRNNAHH P L R V H Q Stop Stop H F S K L P L L P A G I Q A S D S P L E R H L Met Stop R D L QR F S $P \vee H H R S C P S \vee Q R S L N$ Stop R R L A Q P RQALHQIWKQQDRQTARALTFFSS
ST S SLNLSNLINKPLACLQAPCGLT PCTEP

\section{3'5' Frame 2}

L V S Y Y T Met ENG NALLKW Q A L L K Q A G TIGDLFFIKAKPVAEAGTRPSVA GKTLVSFKYSR Met LEETAYE I Met N KSGSLDSGSAAPSQGKLFVEVPGE $K$ Stop F D Met D T D S W L Stop P N K P N Q N G Met R P C Stop L V H P V LF G S P Q R L S R WYLNFSRFFIFYCKRALILCISGLA R L A Stop SKA LE QR W H F G V T C V R D L $P L R Y T A \vee R A H N G I L H \vee G Y \vee G \mid I Q C H$ VNRIGGSSILPHQLADIIRTEVFDIN RTRSVHLKHFIVSLIRCSAGNINGS Stop Stop F Q C Q C I L A Y I F P Y N V G N I T A A V T Met H T I R C G C T N N I F Q S C P C F QPEYRLLILRLRT V T Stop C R G IR Y K GFPLSIIGRALRYNDR Stop I D D G W R SR GRHYTKY G S NKT GRQQER Stop H F F H H Q H P P L I Stop V I Stop Stop T S R W L VYRHPAGSPLVRSL

\section{3'5' Frame 3}

W S V I I R W R T E Met H C Stop N G K P I Stop A NKPEPLVTCSLSRQNPLPRQEPV H L Stop P E K R W Y P S N I L A C W R K P L Met R S Stop T N P A P W I A V L L L H PKA N C SLRCLERSNSIWIQIHGCNQTNQIK T G Stop G H V D W F I P F Y L V L L N G Stop A G G T Stop T S A A S L F F T A S V R Stop Y C V F P D W L V L P E A K P L N S V G T LE Stop R V F V I F P Stop D T L L S VR I Met E S F T L D Met LE L S S V Met L T A Stop E VPPF CRTS LPIS S ARK F L I L IVPEAF I Stop N T LS Stop A L Y A A P P VILTVPDDFS VNASS P T S S H T T LE I L Q L P Stop Q C T P S A A G A P IITFFKVAPAS SR N T G F Stop F S A Stop E P S P N V E G F A T K V F P C P S Stop V VPFGTTIVELTTVGAAAAGITP N Met EATRPADSKSVN IF F I IN ILP Stop FK Stop F D K Q A A L S T G T LR A H P Y Y A Stop

d) Quina és la seqüència d'aminoàcids que pot donar una proteïna, és a dir, que comenci amb un codó d'inici (ATG), acabi amb un codó STOP (TAA, TGA o TAT) i que codifiqui el polipèptid més llarg (Open Reading Frame, ORF)?

L'alumne ha d'enganxar la resposta correcta. La seqüència d'aminoàcids que comença per ATG, acaba en un codó STOP i codifica pel polipèptid més llarg és la que està senyalada en groc. La pro- 
teïna podria començar per qualsevol de les tres metionines, però mirant la distància a seqüències consens, és més probable que comenci per la tercera.

e) En quina cadena es troba $\left(5^{\prime} \rightarrow 3^{\prime}\right.$ o $\left.3^{\prime} \rightarrow 5^{\prime}\right)$ ?

La seqüència es troba en la cadena que va en direcció 5 ' $\rightarrow$ 3'

f) En quina pauta de lectura es troba (1a, 2a o 3a)?

La pauta de lectura és la segona.

\section{Una vegada tenim la seqüència d'aminoàcids, hem de veure quina funció té.}

Hem d'anar a una base de dades que compara la nostra seqüència d'aminoàcids amb altres seqüències de proteïnes ja conegudes. El resultat de la cerca de similituds és una llista ordenada de les proteïnes més semblants. Al costat de cadascuna apareix un número, score. Quant més alt és l'score (el número) més similitud hi ha.

A més obtindràs un gràfic de colors per a veure si l'homologia de seqüència és al llarg de tota la proteïna o només en un fragment localitzat, i els alineaments de la seqüència problema amb cada una de les seqüències de la llista anterior.

- Per arribar a la base de dades clica sobre l'adreça http://www.expasy.ch/tools/

- A continuació clica sobre Similarity searches

- A la nova pàgina clica sobre BLAST at NCBI (fig. 5)

- Protein (ja que tenim la seqüència d'aminoàcids)

- Protein-protein BLAST (blastp)

- Inserir la seqüència d'aminoàcids al requadre en blanc que trobaràs a la pàgina

- Blast (Obtenim les homologies)

g) Quin percentatge d'aminoàcids idèntics (identities) hi ha entre la teva seqüència problema i la més semblant? Per saber-ho pots clicar damunt del número score.

La resposta és $100 \%$.

h) A quin organisme pertany la proteïna més semblant a la teva proteïna problema?

i) A la base de dades posa Bacillus BP-23. En el moment que es va seqüenciar el DNA encara no s'havia classificat el bacteri. Ara se sap que és Paenibacillus barcinonensis (bacteri).

- Isotopldent - Precicts the theoretical isotopic distributon of a peptide, protein Other tools for 2.DE or MS data (vizualisation, anatysis, etc.)

- ImageMaster / Melanie \& - Software for 2-D PAGE anaiysis

- MSight a - Mass Spectrometry lmage

- Make2D-DB II A-A package to build a web-based protecmics database

- DMA $>$ Protein

- Transiate \& - Transiates a nucleotide sequence to a protein sequence

- Graphical Codon Usage Analyser. Displays the codon bias in a graphical mar

- BCM search launcher - Six frame translation of nucleotide sequence(s)

- Backiranslation - Translates a probein sequence bock to a nucleotide sequene - Reverse Translate - Translates a protein sequence back to a nuclectide sequa

- Genewise - Compares a protein sequence to a genomic DNA sequence alov - LabOnWeb-Elongation, expression profiles and sequence analysis of ESTs

- List of gene identification software sces

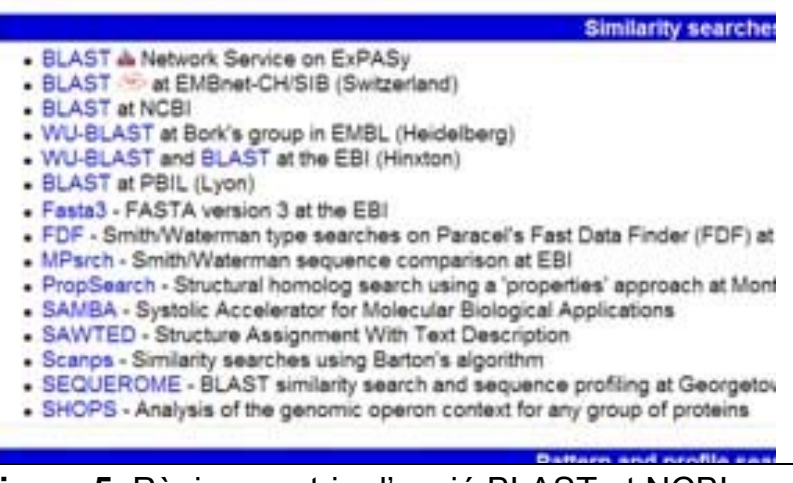

Figura 5. Pàgina per triar l'opció BLAST at NCBI

j) Quina és la funció hipotètica que té nostra proteïna?

La nostra seqüència d'aminoàcids té una elevada homologia amb la seqüència d'aminoàcids d'una pectat liasa (pectinasa). Per tant, la possible funció de nostra proteïna és la de trencar els enllaços que hi ha entre els monòmers del pectat o àcid poligalacturònic. Per saber si aquesta és la seva funció hauríem de fer assajos al laboratori.

\section{k) Quin tipus d'enzim és? Què fa?}

Com hem comentat abans, l'enzim és una pectat liasa. A la unitat d'enzims els alumnes han estudiat que és una liasa, per tant han de saber explicar què fa aquest enzim.

Les liases separen grups sense intervenció de l'aigua (sense hidròlisi), i generalment originen enllaços dobles a la molècula. Per tant, aquest enzim trenca els enllaços que hi ha entre els monòmers de l'àcid poligalacturònic o pectat formant un doble enllaç i sense alliberar aigua (fig. 6).

Relacionat amb aquesta pregunta es podria, comentar la diferència entre una liasa (pectat liasa) i una hidrolasa (poligalacturonasa).

Les hidrolases, també trenquen enllaços, però amb addició d'una molècula d'aigua que s'es- 
cindeix i aporta un $-\mathrm{OH}$ a una part i un $-\mathrm{H}$ a l'altra, com es pot observar a la fig. 6 .

Felicitats, has aconseguit conèixer la funció d'una proteïna desconeguda!

\section{Redacció de la memòria}

La redacció de la memòria és un treball personal. A continuació es proposen alguns suggeriments que poden resultar d'ajuda:

(S'aconsella al professor fer una posada en comú abans d'escriure la memòria).
- Ha de constar de introducció, material i mètodes, resultats, conclusió, discussió i bibliografia.

- Utilitzar el màxim rigor en les frases i expressions. El subjecte de l'oració ha de quedar sempre clar, evitant expressions que puguin donar lloc a més d'una interpretació.

- Poden copiar-se les preguntes dels exercicis en un document de Word, així, a l'hora de respondre un pot ajudar-se fent un copiar i pegar dels resultats obtinguts a través d'Internet.

- Assegurar la perfecta comprensió de les respostes.

- Afegir les adreces d'Internet utilitzades en la bibliografia.

\section{Pectat o Àcid poligalacturònic}
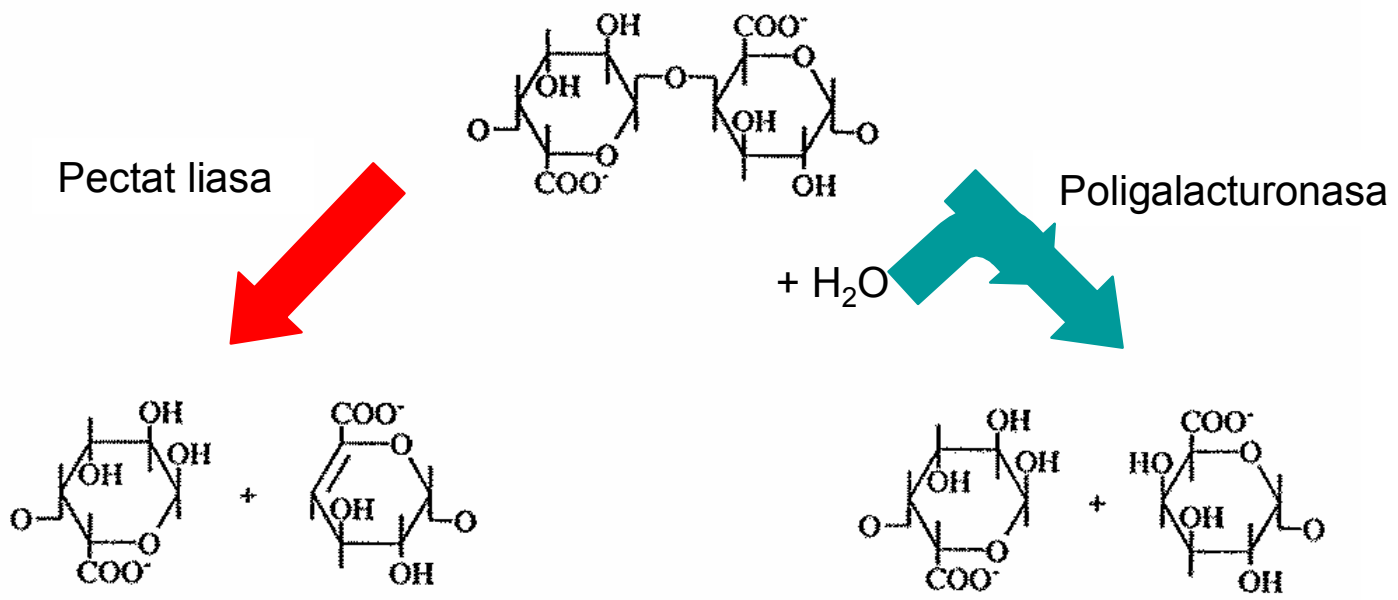

Figura 6. Classificació de les pectinases que actuen sobre àcid poligalacturònic o pectat. Aquestes poden ser: Pectat liasa o Poligalacturonasa. L'enzim trobat trenca els enllaços que hi ha entre els monòmers de l'àcid poligalacturònic o pectat formant un doble enllaç i sense alliberar aigua.

\section{BIBLIOGRAFIA}

Alberts, B., Bray, D., Lewis, J., Raff, M., Roberts, K. i Watson, J. Biología molecular de la célula. 3a ed. Barcelona: Omega, 1996.

Griffiths, A. J. F., Gelbart, W. M., Miller, J. H. i Lewontin, R. C. Genética Moderna. Ed. McGrawHill Interamericana. 2000.

Griffiths, A. J. F., Miller, J. H., Suzuki, D. T., Lewontin, R. C. i Gelbart, W. M.. Genética. Setena edició. Ed. McGraw-Hill Interamericana. 2002.

Klug, W. W. i Cummings, M. R. Conceptos de Genética. Prentice Hall Iberia S. R. L. 1999.
Jimeno, A., Ballesteros, M. I Ugedo, L. Biologia. $2 n$ Batxillerat. Ed. Santillana. Barcelona, 2003.

Thain, M. I Hickman, M. The penguin dictionary of biology. Ed. The penguin books,10a edició. 2000.

\section{GLOSSARI}

Exó: Segments de RNA que contenen la informació per a la síntesi de proteïnes. Seqüències amb sentit.

Gen: Unitat fonamental, física i funcional, de la herència que transmet la informació d'una genera- 
ció a la següent. Fragment d'àcid nucleic, generalment, ADN, que duu informació per a un caràcter.

Genoma: Material genètic complet d'una dotació cromosòmica.

Intró: Fragment del gen sense funció coneguda, que es transcriu però que el producte de la seva transcripció és eliminat del mRNA madur. Seqüència sense sentit que no codifica per cap proteïna.

Organismes transgènics: Organismes amb gens procedents d'altres organismes.

Pauta de lectura o open reading frame (ORF): És la porció del genoma d'un organisme que conté una seqüència de bases que podria codificar potencialment una proteïna.

Plasmidi: Molècula extracromosòmica de DNA amb capacitat de replicació autònoma.

SNPs (Single Nucleotide Polymorphism): Variants polimòrfiques dels nucleòtids d'un gen.

Splicing: Procés d'eliminació d'introns i unió de les regions informatives o exons.

Splicing alternatiu: Procés d'eliminació d'introns i unió de les regions informatives o exons, que pot variar segons la proteïna que codifica. 


\title{
Annex: Pràctica per a l'alumnat Quina és la funció del gen clonat?
}

\author{
Margarita Soriano i Francesca Guerola
}

\section{Objectiu}

En la següent pràctica volem replicar, transcriure i traduir un gen clonat en un plàsmid. D'aquesta manera podrem conèixer la seqüència d'aminoàcids i a partir d'ella identificar la seva funció.

A partir del fragment de DNA seqüenciat inserit en el plàsmid, hauràs de:

- replicar el fragment de DNA,

- transcriure la seqüència de nucleòtids,

- traduir la seqüència de nucleòtids,

- saber quina és la part del fragment de DNA que correspon al gen que volem investigar,

- i conèixer la funció de la proteïna.

Cal tenir en compte que el DNA bacterià no té introns. Això significa que cada gen codifica una proteïna.

\section{Materials}

Les bases de dades $\mathrm{i}$ eines que necessitaràs per a resoldre l'activitat les pots trobar al full de pràctiques a Protein Analysis System (ExPASy: http://www.expasy.ch/tools/). Aquesta serà la pàgina a la que pots dirigir-te per a triar l'eina adequada en cada ocasió i respondre les preguntes plantejades.

A més, has de tenir en compte que:

- Al llarg de la sessió has de guardar les adreces utilitzades per posar-les com a bibliografia.

- Cal guardar tota la informació que trobis en un disc o pen drive per a poder respondre així les preguntes i presentar un informe final de les pràctiques. (No has de deixar res teu en el disc dur de l'ordinador ja que l'endemà potser no li trobessis).

\section{Mètode}

A partir d'una seqüència de nucleòtids hem de trobar el gen que volem investigar.

tcaggctccgtacaaggggtgagcccgcagggtgcctgtagacaa gccagcggcttgtttatcaaattacttaaattaagggaggatgttgat gatgaaaaaaatgttaacgctcttgctgtctgccggtcttgttgcttcc atatttggtgtaatgcctgccgcggctgcgccaaccgtcgtcaattcaa cgatcgttgtaccgaagggcacgacctatgatggacaggggaaaa cctttgtagcgaatccctctacattaggtgacggttctcaagcggagaa tcagaagcctgtattccggctggaagcaggggcaactttgaaaaatg ttattattggtgcacccgcagcggatggtgtgcattgttacggcagctgt aatatttccaacgttgtatgggaagatgtaggcgaggatgcattgaca ctgaaatcatcaggaaccgttaatattaccggcggagcagcgtataa ggcttacgataaagtgtttcagatgaacgcttcgggtacgattaatatc aaaaacttccgtgcggatgatatcggcaagctggtgcggcaaaatg gaggaacctcctatgcggttaacatgacactggataattccaacatat ccaacgtgaaggattccattatgcgcacggacagcagtgtatctcaa gggaagatcacgaacacacgttactccaaagtgccaacgctgttca agggctttgcttcaggcaagacgagccagtccggaaatacacagta ttaacgcacgcttgcagtaaaaaataaagaagcggctgaagttcaa gtaccacctgctcagccgttgaggagaaccaaataaaacgggatg aaccagtcaacatggcctcatcccgtttgatttggtttgtttggttacagc catgaatctgtatccatatcgaattacttctctccaggcacctcaacga acagtttgccttgggatggagcagcagaaccgctatccaaggagcc ggatttgttcatgatctcataagcggtttcctccagcatgcgagaatattt gaaggataccagcgttttccggctacagatggacgggttcctgcctc ggcaacgggttttgccttgataaagaacaggtcaccaatggttccgg cttgtttgctcagattggcttgccatttcaacagtgcatttccgttctccatc gtataataactgaccaga

1. Abans de començar la feina practicarem la replicació, transcripció i traducció a partir d'una petita seqüència de nucleòtids.

I) Copia la seqüència de nucleòtids assenyalada en negreta $\mathrm{i}$ fes la cadena complementària d'aquesta seqüència. A continuació transcriu i tradueix la seqüència utilitzant una pauta de lectura (fig. 1).

m) De la seqüència estudiada, on podria començar una hipotètica proteïna? 
EI DNA bacterià presenta una estructura circular de doble cadena. Això significa que el nostre gen pot estar en qualsevol de les dues cadenes. Com que les seqüències poden ser molt llargues, podem tenir la seqüència del gen en la cadena original o en la complementària, i a la vegada cadascuna pot tenir tres pautes de lectures o ORF (open reading frame), en els laboratoris es treballa amb programes que ens transcriuen i tradueixen la seqüència de la hipotètica proteïna.

n) A l'exercici a) has traduït la seqüència de $m R$ NA. A continuació, torna a traduir la seqüència de mRNA utilitzant les altres 2 pautes de lectura. La seqüència d'aminoàcids és la mateixa?

2. La seqüència de nucleòtids completa (pàgina anterior) la replicarem, transcriurem i traduirem amb un programa informàtic per trobar la seqüència de la hipotètica proteïna:

- Primer, anirem a la següent pàgina:

http://www.expasy.ch/tools/

- Clicarem sobre la següent opció:

DNA $\rightarrow$ Protein

- A continuació farem dos clics sobre: Translate

- Enganxa la seqüència de nucleòtids en el quadre en blanc

- Per últim clica sobre Translate sequence

o) Enganxa els resultats

p) Quina és la seqüència d'aminoàcids que pot donar una proteïna, és a dir, que comenci amb un codó d'inici (ATG), acabi amb un codó de STOP (TAA, TGA o TAT) i que codifiqui el polipèptid més llarg (ORF)?

q) En quina cadena es troba $\left(5^{\prime} \rightarrow 3^{\prime} \circ 3^{\prime} \rightarrow 5^{\prime}\right)$ ?

r) En quina pauta de lectura es troba (1a, 2a o 3a)?

\section{Una vegada tenim la seqüència d'aminoàcids, hem de veure quina funció té}

Hem d'anar a una base de dades que compara la nostra seqüència d'aminoàcids amb altres seqüències de proteïnes ja conegudes. El resultat de la cerca de similituds és una llista ordenada de les proteïnes més semblants. Al costat de cadascuna apareix un número, score. Com més gran és l'score (el número) més similitud hi ha.
A més obtindràs un gràfic de colors per veure si l'homologia de seqüència és al llarg de tota la proteïna o només en un fragment localitzat, i els alineaments de la seqüència problema amb cada una de les seqüències de la llista anterior.

- Per arribar a la base de dades clica sobre l'adreça http://www.expasy.ch/tools/

- A continuació clica sobre Similarity searches

- A la nova pàgina clica sobre BLAST at NCBI

- Protein (ja que tenim la seqüència d'aminoàcids)

- Protein-protein BLAST (blastp)

- Inserir la seqüència d'aminoàcids al requadre en blanc que trobaràs a la pàgina

- Blast (Obtenim les homologies)

s) Quin percentatge d'aminoàcids idèntics (identities) hi ha entre la teva seqüència problema i la més semblant? Per saber-ho pots clicar damunt del número score.

t) A quin organisme pertany la proteïna més semblant a la teva proteïna problema?

u) Quina és la funció hipotètica que té nostra proteïna?

v) Quin tipus d'enzim és? Què fa?

Felicitats, has aconseguit conèixer la funció d'una proteïna desconeguda!

\section{Redacció de la memòria}

La redacció de la memòria és un treball personal. A continuació es proposen alguns suggeriments que poden resultar útils:

- Ha de constar d'introducció, material i mètodes, resultats, conclusió, discussió i bibliografia.

- Utilitzar el màxim rigor en les frases $\mathrm{i}$ expressions. El subjecte de l'oració ha de quedar sempre clar, evitant expressions que puguin donar lloc a més d'una interpretació.

- Poden copiar-se les preguntes dels exercicis en un document de Word. Així a l'hora de respondre hom pot fer servir el copiar $i$ enganxar amb els resultats obtinguts a través d'Internet.

- Assegurar la perfecta comprensió de les respostes.

- Afegir les adreces d'Internet utilitzades en la bibliografia 


\begin{tabular}{|c|c|c|c|c|c|c|c|c|c|c|}
\hline & \multicolumn{7}{|c|}{ Segona lletra } & & \\
\hline & & $U$ & $c$ & & 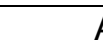 & A & $c$ & & & \\
\hline \multirow{4}{*}{ 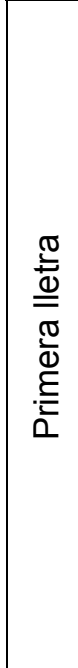 } & $U$ & $\left.\begin{array}{l}\text { UUU } \\
\text { UUC }\end{array}\right\}$ Fen & $\begin{array}{l}\text { UCU } \\
\text { UCC } \\
\text { UCA } \\
\text { UCG }\end{array}$ & Ser & $\begin{array}{l}\text { UAU } \\
\text { UAC } \\
\text { UAA } \\
\text { UAG }\end{array}$ & $\begin{array}{l}\text { Tir } \\
\text { Stop }\end{array}$ & $\begin{array}{l}\text { UGU } \\
\text { UGC } \\
\text { UGA } \\
\text { UGG }\end{array}$ & $\begin{array}{l}\text { GIn } \\
\text { Stop } \\
\text { Trp }\end{array}$ & $\begin{array}{l}U \\
C \\
A \\
G\end{array}$ & \multirow{4}{*}{ 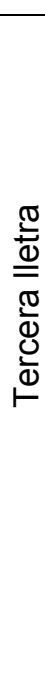 } \\
\hline & C & $\left.\begin{array}{l}\text { CUU } \\
\text { CUC } \\
\text { CUA } \\
\text { CUG }\end{array}\right\}$ Leu & $\begin{array}{l}\text { CCU } \\
\text { CCC } \\
\text { CCA } \\
\text { CCG }\end{array}$ & Pro & $\left.\begin{array}{l}\text { CAU } \\
\text { CAC } \\
\text { CAA } \\
\text { CAG }\end{array}\right\}$ & $\begin{array}{l}\text { His } \\
\text { Gln }\end{array}$ & $\begin{array}{l}\text { CGU } \\
\text { CGC } \\
\text { CGA } \\
\text { CGG }\end{array}$ & Arg & $\begin{array}{l}\text { U } \\
\text { C } \\
\text { A } \\
\text { G }\end{array}$ & \\
\hline & A & $\left.\begin{array}{l}\text { AUU } \\
\text { AUC } \\
\text { AUA }\end{array}\right\} \| l e$ & $\begin{array}{l}\text { ACU } \\
\text { ACC } \\
\text { ACA } \\
\text { ACG }\end{array}$ & Tre & $\left.\begin{array}{l}\text { AAU } \\
\text { AAC } \\
\text { AAA } \\
\text { AAG }\end{array}\right\}$ & $\begin{array}{l}\text { Asn } \\
\text { Lis }\end{array}$ & $\left.\begin{array}{l}\text { AGU } \\
A G C \\
A G A \\
A G G\end{array}\right\}$ & $\left\{\begin{array}{l}\text { Ser } \\
\text { Arg }\end{array}\right.$ & $\begin{array}{l}\text { U } \\
C \\
A \\
G\end{array}$ & \\
\hline & G & $\left.\begin{array}{l}\text { GUU } \\
\text { GUC } \\
\text { GUA } \\
\text { GUG }\end{array}\right\}$ Val & $\begin{array}{l}\text { GCU } \\
\text { GCC } \\
\text { GCA } \\
\text { GCG }\end{array}$ & Ala & $\left.\begin{array}{l}\text { GAU } \\
\text { GAC } \\
\text { GAA } \\
\text { GAG }\end{array}\right\}$ & $\begin{array}{l}\text { Asp } \\
\text { Glu }\end{array}$ & $\begin{array}{l}\text { GGU } \\
\text { GGC } \\
\text { GGA } \\
\text { GGG }\end{array}$ & Gli & $\begin{array}{l}\text { U } \\
C \\
A \\
G\end{array}$ & \\
\hline
\end{tabular}

Figura 1. Pauta per a la lectura de seqüències de mRNA. 